\title{
AN ADAPTED MODEL OF BURNOUT FOR EMPLOYEES AT A HIGHER EDUCATION INSTITUTION IN SOUTH AFRICA
}

\author{
S.E. COETZEE \\ S. ROTHMANN \\ Workwell: Research Unit for People, Policy and Performance, \\ North-West University, Potchefstroom
}

\begin{abstract}
The objectives of this study were to test an adapted four-factor model of burnout consisting of Exhaustion, Cynicism, Professional Efficacy and Cognitive Weariness for employees of a higher education institution in South Africa and to determine differences in burnout levels between different language groups and employees with different years of experience at the institution. A cross-sectional survey design $(N=372)$ was used. The Maslach Burnout Inventory - General Survey, the Cognitive Weariness Scale and a biographical questionnaire were administered. Structural equation modelling confirmed the hypothesised four-factor model of burnout. The scales showed acceptable internal consistencies. Analysis of variance revealed differences in burnout and cognitive weariness for groups with different languages and different years of experience at the institution.
\end{abstract}

\section{OPSOMMING}

Die doelstellings van hierdie studie was om 'n aangepaste vierfaktormodel van uitbranding bestaande uit Uitputting, Sinisme, Professionele Doeltreffendheid en Kognitiewe Vermoeidheid vir werknemers van 'n hoëronderwysinstansie in Suid-Afrika te toets en om te bepaal of verskillende taalgroepe en werknemers met verskillende jare ervaring by die instansie verskille in uitbrandingsvlakke ervaar. ' $n$ Dwarssneeopname-ontwerp $(N=372)$ is gebruik. Die Maslach Uitbrandingsvraelys - Algemene Opname, die Kognitiewe Vermoeidheidskaal en 'n biografiese vraelys is afgeneem. 'n Vierfaktormodel van uitbranding is met strukturele vergelykingsmodellering bevestig. Die skale het aanvaarbare interne konsekwentheid getoon. Variansie-analise het verskille ten opsigte van uitbranding en kognitiewe vermoeidheid by verskillende taalgroepe en groepe met verskillende jare ervaring by die instansie opgelewer.

The environment in which employees in South Africa and elsewhere in the world function, demands more of them than had been the case in any previous period. The employment relationship is changing, altering the type of work that people do, when they work and how much they do (Barling, 1999). Some employees also face diminished choice and control in that they are forced to take on hours and working arrangements that are against their preferences (Turner, Barling \& Zacharatos, 2002). Additional unpredictability results as many employers move toward greater flexibility by expanding and shrinking the work force to correspond with shifting production and service demands, resulting in loss of control over working hours and in job insecurity (Martin, 1997). Many organisations have implemented practices that attempt to reduce costs and increase productivity, which often leads to a mentality that favours profitability over the welfare of people (Turner, Barling \& Zacharatos, 2002).

These changes in the world of work also impact on higher education institutions that have to adapt unremittingly in order to survive (Gilbert, 2000). A global phenomenon in the changing landscape of higher education institutions is the expansion from elite systems to institutions of mass student numbers (Gilbert, 2000; Kistan, 1999; Kraak, 2000). Other consequences are lifelong learning (Shortlidge, 2003; Wallace \& Ipson, 1992), adult learning (Kraak, 2000), internet-based education and training (Gilbert, 2000), formation of strategic alliances on international level (Rowley, 2000), new trends in teaching and learning (Kistan, 1999; Kraak, 2000), changes in the market place (Blackmore, 2001; Brown, 1999; Gilbert, 2000; Kistan, 1999; Lomas, 1997; Robertson, 1998; Rowley, 2000), the growth of alternative systems of education, and the new demands and needs of society (Kistan, 1999). These changes will have a direct impact on the experience of work of employees at higher education institutions. Zhao and Guo (2002) cautioned that to become more competitive in the era of globalisation, more educated and better trained work forces are required.

Requests for copies should be addressed to: $S$ Rothmann, Department of Industrial Psychology, North-West University, Potchefstroom Campus, Private Bag X6001, Potchefstroom, 2520
The landscape of higher education in South Africa is also changing. Since 1994, the aim of the post-apartheid government has been the redress of the apartheid legacy in an attempt to move toward a democratic society (Cross, Mungadi \& Rouhani, 2002). One of the focus areas of redress is the education system. At an institutional level this boils down to the introduction of policies and mechanisms aimed at redress on different levels and demands in terms of access to education (Kraak, 2000). This has resulted in a restructuring of the higher education system in South Africa, which poses the following challenges to the management as well as the employees of tertiary institutions: New organisational cultures have to be introduced; values, cultural norms and organisational support systems are subjected to ongoing changes; peer support within the organisation is challenged with issues like equity, diversity and resistance; establishing an organisational climate is continuously and inevitably influenced by ongoing change.

Higher education institutions can make an important contribution to the reconstruction and development of South Africa (Marais, Grobbelaar \& Potgieter, 1997). However, of great importance are those responsible for producing the outcomes of higher education institutions. Administrators (Blaise, 1996; Goldstein, 1992), lecturers/teachers (Schnacke, Martray \& Heck, 1994; Seldin, 1991) and support staff (Alexy, 1991; Glasgow, Terborg, Hollis, Severson, Boles, 1995) comprise the "human capital" of an education institution and therefore it is important to care for these groups of people (Sackney, Noonan \& Miller, 2000).

The current changes and demands in the higher education scenario will inevitably have an impact on the levels of burnout of employees at higher education institutions. Meléndeze and De Guzman (1983, p. 1) define burnout as a "state of mind that affects people who work with other people and give much more than what they get in return from their colleagues, friends, supervisors and clients", and include symptoms such as lack of enthusiasm for work, helplessness and frustration. A more recent and elaborated definition on burnout is that of Schaufeli and Enzmann (1998, p. 36). They define burnout as "a persistent, 
negative, work related state of mind in 'normal' individuals that is primarily characterized by exhaustion, which is accompanied by distress, a sense of reduced effectiveness, decreased motivation, and the development of dysfunctional attitudes and behaviors at work". According to Levert, Lucas and Ortlepp (2000), burnout can be seen as the end result of consistently unmediated or unsuccessful attempts of the individual at mediating stressors in the environment.

Burnout affects the individual on a cognitive, affective (motivational), physical and behavioural level as a result of a general breakdown in defences against prolonged job-stressors (Brill, 1984). This breakdown occurs gradually and often remains unnoticed for a long time, perpetuated by ineffective coping strategies and frustrated intentions brought about by the subjective experience of work-reality. The gradual depletion of emotional resources results in a sense of reduced effectiveness, decreased motivation and the development of dysfunctional behaviours and attitudes at work (Schaufeli \& Enzmann, 1998).

Originally restricted to the helping professions, burnout is now recognised as a phenomenon found in a variety of occupational groups (Cordes \& Dougherty, 1993). Research over the last three decades has shown that the consequences of burnout are not just limited to the individual's subjective experience, but also to various organisational outcomes. Burnout has been associated with reduced organisational efficiency and work-related problems such as employee turnover, low morale, poor quality of care, lowered productivity, absenteeism and interpersonal problems (Levert et al., 2000; Rosse, Boss, Johnson \& Crown, 1991). Maslach and Jackson (1986) suggested that burnout could lead to a deterioration in the quality of care or service that is provided by staff. It correlates with various self-reported indices of personal dysfunction, increased use of alcohol and drugs, and marital and family problems (Maslach \& Jackson, 1986). The study of burnout, therefore, certainly seems to be beneficial to organisations and the general welfare of companies and their workers in various organisational contexts.

Probably the most influential development in terms of scientific exploration of the burnout construct was the development of the Maslach Burnout Inventory (MBI) (Maslach \& Jackson, 1986). Initially two versions of the MBI were developed, namely the MBI-ED (Educators) and MBI-HSS (Human Services Survey). These versions measure Emotional Exhaustion, Depersonalisation and Personal Accomplishment. When slightly adapted versions of he MBI-HSS/ED were used outside the targeted professions, psychometric results were rather disappointing (e.g. Boles, Dean, Ricks, Short \& Wang, 2000; Evans \& Fisher, 1993). The fact that, obviously, the MBI should be used exclusively in those occupational contexts it has been designed for - human services and education - has led to the development of a version that can be used universally: The MBI - General Survey (MBI-GS). The MBI-GS contains dimensions similar to the original version, except that the items do not explicitly refer to recipients or students (Schaufeli, Leiter, Maslach \& Jackson, 1996). Accordingly, the dimensions of the MBI-GS have been renamed slightly as: exhaustion, cynicism and professional efficacy. In the current study, the MBI-GS has been used.

The importance of establishing a reliable and valid instrument to assess burnout in a higher education institution is evident not only for the purpose of empirical research, but also ultimately for individual assessment. When determining factorial validity, confirmatory factor analysis (through structural equation modelling) should be used, because exploratory factor analysis shows some weaknesses (Byrne, 1991). As such, a considerable amount of research seems to support the psychometrical soundness of the $\mathrm{MBI}$ in various occupational settings.
Regarding the MBI-GS, satisfactory internal consistencies for all the subscales were found (Leiter \& Schaufeli, 1996; Schutte, Toppinen, Kalimo \& Schaufeli, 2000). The three-factor structure of the MBI-GS is generally confirmed (Taris, Schreurs \& Schaufeli, 1999; Schutte et al., 2000), although different results in specific samples are found occasionally. For example, Salanova and Schaufeli (2000) observed four factors in Spanish workers.

A systematic negative finding is that one particular cynicism item (item 13 (sic!), 'I just want to do my job and not to be bothered') seems to be unsound (e.g. Schutte et al., 2000). In their studies Schaufeli, Leiter and Kalimo (1995) and Leiter and Schaufeli (1996) also found that this item had the lowest factor loadings of the three sub-scales. Therefore, this item was deleted in the Dutch version of the MBI-GS (Schaufeli \& Van Dierendock, 2000). The three-factor structures of the original version as well as the general version seem to be invariant across countries (MBI-HSS: Enzmann, Schaufeli \& Girault, 1995; MBIGS: Schutte et al., 2000) and occupations (Bakker, Demerouti \& Schaufeli, 2002; MBI-ED: Byrne, 1991; MBI-GS: Leiter \& Schaufeli, 1996; Bakker, Demerouti \& Schaufeli, 2002).

In South Africa few studies regarding the validity, reliability and establishment of norms for various occupational settings using the MBI-GS could be found (Rothmann, Jackson \& Kruger, 2003; Rothmann \& Jansen van Vuuren, 2002; Rothmann \& Malan, 2003; Storm \& Rothmann, 2003). A lack of research in this area within the South African higher education context necessitates the current research.

Rothmann (2003) stressed the need for burnout research in South Africa in stating that serious limitations of burnout research in South Africa include poorly designed studies (i.e. small sample size), a lack of sophisticated statistical analysis (i.e. confirmatory factor-analytical analysis by means of structural equation modelling) and poorly controlled studies.

Despite the fact that, from a psychometrical point of view, the MBI is a good tool for assessing burnout, a basic problem remains. Because of the absolute predominance of the MBI, the concept is narrowed to the three dimensions that are included in the MBI, namely exhaustion, cynicism (or depersonalization), and reduced professional efficacy (or personal accomplishment). Although this common standard has the advantage that findings across studies can be compared straightforwardly, for instance by using meta-analyses, the narrow focus remains an issue. This is all the more serious since the MBI is neither grounded in firm clinical observation nor based on sound theorising. Instead, it has been developed inductively by factor-analysing a rather arbitrary set of items (Schaufeli, 2003).

Clinical experience shows that burned-out employees who receive psychotherapeutic treatment report a host of distress complaints that are for a large part similar to those subsumed under the ICD-10 diagnostic label of neurasthenia (Schaufeli, Bakker, Schaap, Kladler \& Hoogduin, 2001). Depending on one's definition, such atypical distress symptoms as sleep disturbances, irritability, inability to relax and tension headaches can either be considered elements of burnout, consequences of burnout or accompanying symptoms. More specifically, clinical practice suggests that employees suffering from severe burnout are characterised by cognitive impairment, and report symptoms such as inability to concentrate, forgetfulness and difficulties with solving complex tasks (Hoogduin, Schaap, Methorst, Peters Van Neyenhof \& Van de Griendt, 2001). Such cognitive symptoms typically occur when one feels exhausted.

Recently, Van Horn, Taris, Schaufeli and Schreurs (in press) developed an alternative exhaustion scale that was labelled 'The Cognitive Weariness Scale' which includes items such as "I have trouble concentrating" and "I'm absent-minded". Their study 
among teachers showed that this scale was reliable and that it was substantively correlated with all MBI burnout scales, but particularly with emotional exhaustion. Hence, based on clinical experience, the MBI burnout concept should be supplemented by cognitive exhaustion or weariness, and perhaps also with distress symptoms (Schaufeli, 2003). The Cognitive Weariness Scale was included for the purposes of this study.

Burnout can be enhanced by biographical factors. Biographical factors that could explain burnout include age, work experience and gender. Burnout is observed more often among younger employees compared with those older than 30 years, and burnout is negatively related to work experience (Cherniss, 1980; Künzel \& Schulte, 1986; Maslach, Jackson \& Leiter, 1996). Zijlstra and De Vries (2001), however, found that older, more experienced, single workers who experienced a high workload were significantly more at risk compared to younger, less experienced, married workers with a low workload. Women tend to score higher on emotional exhaustion, whereas men score higher on depersonalization (Schaufeli \& Enzman, 1998). Cash (1988) found that individuals with a higher level of education were more prone to burnout, possibly due to the higher expectations of both the individual and the organisation of these individuals.

The objectives of this study were to determine the factorial validity and internal consistency of an adapted version of the Maslach Burnout Inventory - General Survey (MBI-GS) (by including a Cognitive Weariness Scale), for employees at a higher education institution in South Africa and to determine differences in burnout levels among different biographical groups.

\section{The Maslach Burnout Inventory - General Survey}

In the beginning of the eighties, the first easy-to-administer selfreport inventories on burnout appeared - most notably the Maslach Burnout Inventory (Maslach \& Jackson, 1981). This initiated a major stimulation of the scientific interest in burnout. It is estimated that the MBI was used in over $90 \%$ of the empirical publications on burnout since the mid-eighties (Schaufeli \& Enzmann, 1998). According to Koeske and Koeske (1993), the MBI has taken a central position in shaping the theoretical debate over the nature of burnout.

With the introduction of the MBI-GS, the three burnout dimensions can be measured independently from the professional context. The MBI-GS was designed to measure burnout universally by means of three subscales, namely exhaustion, cynicism and professional efficacy. The exhaustion items are generic and refer to fatigue without direct reference to service recipients as its source; the cynicism items reflect a distant attitude towards one's work instead of towards the people one is working with; and the professional efficacy items encompass the non-social aspects of occupational accomplishments instead of exclusively focusing on the social aspects of these accomplishments. Hence, the MBI-GS has a broader scope than the original MBI (Schaufeli, 2003). Or put the other way around, the original MBI dimensions can be seen as manifestations of a more general burnout symptomatology; that is, emotional exhaustion is a particular kind of exhaustion (namely caused by emotional demands), depersonalisation is a particular kind of cynicism (namely directed towards recipients), and personal accomplishments is a particular kind of professional efficacy (namely in relation to recipients).

An advantage is that the MBI-GS can be used both in human services and non-human services samples, so that they can be directly compared. For instance, Taris et al. (1999) showed that, psychometrically speaking, the MBI-GS performed equally well in a sample of software engineers as among university teaching staff, but that levels of exhaustion and cynicism were significantly higher in the former sample compared to the latter, whereas the reverse was true for professional efficacy. In addition, their theoretical model fitted equally well across both samples: exhaustion was predicted by job demands and lack of decision latitude, while cynicism and professional efficacy were predicted by lack of decision authority and a lack of skill discretion. In other words, the study of Taris et al. (1999) shows that the MBI-GS can be used to measure burnout among educators and corporate employees and that - despite differences in levels - burnout is predicted by similar variables in both samples. This is another indication that burnout is not a typical helper syndrome. Other studies, using the MBI-GS have also demonstrated the consistency of the burnout construct across human services and non-human services samples (e.g. Bakker et al., 2002; Leiter \& Schaufeli, 1996).

In the literature regarding the MBI-GS, satisfactory internal consistencies ranging from 0,73 (Cynicism) to 0,91 (Exhaustion) were found (Leiter \& Schaufeli, 1996). Reliability analysis done by Schutte et al. (2000) showed that the Exhaustion and Professional Efficacy sub-scales were sufficiently internally consistent, but that one Cynicism item (item 13) should be removed in order to increase the internal consistency beyond the criterion of 0,70 . According to them, this might be caused by the ambivalence of the particular item: "I just want to do my job and not be bothered". In their studies, Schaufeli et al. (1995) and Leiter and Schaufeli (1996) also found that this item had the lowest factor loadings of the three sub-scales.

Four studies that used the MBI-GS in South African samples were found. In a sample of senior managers in a manufacturing industry, Rothmann and Jansen van Vuuren (2002) found satisfactory alpha coefficients: Exhaustion $=0,79$; Cynicism $=$ 0,84 (after item 13 had been omitted); and Professional Efficacy $=0,84$. Rothmann and Malan (2003) found higher alphas (Exhaustion $=0,98$; Cynicism $=0,76$; Professional Efficacy $=$ 0,85 ), while Rothmann et al. (2003) found lower alphas for Cynicism $(0,72$ after item 13 had been omitted) and Professional Efficacy $(0,69)$. Storm and Rothmann (2003) found alpha coefficients of 0,88 (Exhaustion), 0,78 (Cynicism) and 0,79 (Professional Efficacy) in a sample of 2396 police officers in South Africa. They also confirmed the three-factor structure of the MBI-GS.

A large body of research has addressed the factor structure of the MBI-HSS (Maslach \& Jackson, 1986; Maslach, 1993), but it seems as if there is a paucity of research on the internal and external validity of the MBI-GS (Taris et al., 1999). Confirmatory factor analysis done by Schutte et al. (2000) showed that the three-factor model was clearly superior to alternative one-factor and two-factor models. Schaufeli, Martinez, Pinto, Salanova and Bakker (2002) confirmed these findings. Leiter and Schaufeli (1996) employed confirmatory factor analysis using linear structural equation modelling and also confirmed a three-factor structure. Similar results were obtained by Taris et al. (1999).

Confirmatory factor analyses by Rothmann et al. (2003), Rothmann and Jansen van Vuuren (2002) and Rothmann and Malan (2003) consistently showed low loadings on item 13 of the MBI-GS on Cynicism. Storm and Rothmann (2003) used structural equation modelling (SEM) methods as implemented by AMOS (Arbuckle, 1997) to test the factorial model for the MBI-GS on a random, stratified sample in the South African Police Services $(\mathrm{N}=2396)$. Prior to testing the three-factor model of burnout, a one-factor model was tested. However, the onefactor model showed poor fit, while a three-factor model, using 15 of the original items, resulted in a good fit.

Cognitive weariness refers to the lack of capacity to take up new information and loss of concentration at work. Cognitive weariness was devised as an analogue to Maslach's (1993) emotional exhaustion concept. Whereas the latter concept taps feelings of work-related fatigue (thus reflecting the tiredness- 
vigour dimension of affect), cognitive weariness specifically reflects employee's cognitive functioning, especially the degree to which workers are able to take up new information and are able to concentrate on their work (Van Horn et al., in press). Empirical research has shown that (affective) well-being on the one hand and indicators of cognitive functioning (e.g. "the number of minor everyday errors people make", Broadbent, Cooper, FitzGerald \& Parkes, 1982) and self-reports about one's ability to concentrate and decision making skills (e.g. Goldberg, 1972; Wissing \& Van Eeden, 2002) on the other are correlated. As cognitive functioning is relevant for many of today's jobs (e.g. $56 \%$ of the European workers report that they must solve complex tasks (Merllié \& Paoli, 2001), it was decided that this dimension deserved an additional place in the model of burnout (Schaufeli, 2003).

\section{Burnout and biographical factors}

Schaufeli (2003) estimated the prevalence of burnout amongst the workforce in the Netherlands at about $4-7 \%$ of the working population, amounting to about $10 \%$ in specific occupations. He warned that it should be kept in mind that because of the healthy worker effect, these rates are inflated and most likely represent an underestimation of the true number of burnout cases. Landsbergis (2003) stated that there is indeed no a priori reason why the experience of burnout should be restricted to a particular country or cultural setting, all the more because the organisation of work undergoes similar sweeping changes across the globe, especially in developing countries. Research has shown that biographical factors can enhance burnout. Using the MBI-GS in a national, representative sample of the Dutch working population $(N=1,129)$, Zijlstra and De Vries (2001) found that no differences in burnout levels were observed between males and females, but that older, more experienced single workers who experienced high workload were significantly more at risk compared to younger, less experienced, married workers who experience low workload.

In order to determine a risk profile of employees at any organisation, biographical indicators of burnout can be helpful and can be used to direct future interventions. Factors like job/role demand stressors, individual demand stressors, participation, career progress opportunities and supervisory style can act as antecedents of burnout (Posig \& Kickul, 2003). Biographical information of participants can shed light on which antecedent factors are prevalent in an organisation and can be utilised in directing both proactive and reactive interventions. This information on burnout should be relevant for all organisations, especially in the light of recent evidence which suggests that objective work characteristics (i.e. job autonomy, workload) which can be influenced by management are related to burnout (Aiken, Clarke, Sloane, Sochalski \& Silber, 2002; Taris, Stoffelson, Bakker, Schaufeli \& Van Dierendonck, 2002).

Referring to the literature study of this research it can be expected that regarding biographical characteristics of the population the following differences may be expected: It seems as if younger employees with less work experience will be more prone to burnout than those older than 30 years (Cherniss, 1980; Künzel \& Schulte, 1986; Maslach, Jackson \& Leiter, 1996). This implies that it can be expected that younger employees will reflect higher levels of burnout, and also that those with fewer years of experience at the institution will reflect higher levels of burnout.

With regard to differences between employees from different language groups, indications are that, even though not much research evidence is available, no significant differences regarding burnout patterns and burnout levels could be found internationally between different cultures (Enzmann et al., 1995; Schutte et al., 2000). Therefore, it can be expected that there would be no significant differences between language groups. With regard to gender differences, Schaufeli and Enzmann (1998) found that women tend to score higher on emotional exhaustion, whereas men score higher on depersonalisation. Based on this, it can be expected that women will reflect higher levels of burnout than their male counterparts.

The hypotheses of this study are as follows:

H1: Burnout, as measured by the MBI-GS and Cognitive Weariness Scale, can be defined as a four-dimensional construct with acceptable levels of internal consistency for each of its subscales, namely Exhaustion, Cynicism, Professional Efficacy and Cognitive Weariness.

H2: In terms of burnout levels of employees, significant differences based on biographical characteristics like age, language group, gender and years of experience at the institution exist. Younger employees will reflect higher levels of burnout, and those with fewer years of experience at the institution have will reflect higher levels of burnout. No significant differences regarding language group are expected. It can be expected that women will reflect higher levels of burnout than their male counterparts.

\section{METHOD}

\section{Research design}

A cross-sectional survey design was used. Cross-sectional designs are appropriate where groups of subjects at various stages of development are studied simultaneously, whereas the survey technique of data collection gathers information from the target population by means of questionnaires (Burns \& Grove, 1993). Although Schaufeli and Enzmann (1998) criticise the use of cross-sectional designs in the study of burnout research and recommend that experiments and longitudinal designs should be used as far as possible, it offers the best possible design for the validation of the adapted version of the MBI-GS.

\section{Participants}

AThe study population consisted of academic and administrative staff at a tertiary institution in South Africa participated in the study. A total of 820 questionnaires were sent out: academic staff $(N=320)$; and administrative staff $(N=500)$. A total of 372 completed questionnaires were received back. This comprised 175 questionnaires from academic and 197 questionnaires from administrative staff members, giving a total response rate of $45,36 \% \quad(47,04 \%$ for academic staff and $52,96 \%$ for administrative staff).

Females constituted $63 \%$ of the participants. Different language groups were included in the study. A total of $55 \%$ of the participants were Afrikaans-speaking; 19\% were Englishspeaking; $11 \%$ Setswana-speaking; and $15 \%$ spoke other indigenous languages. The majority (44\%) of the participants were married. In total, $25 \%$ of the population had obtained master's (or related) degrees and/or higher qualifications. $47 \%$ indicated that they were improving their qualifications. $34 \%$ of the participants had been at the institution for 10 or more years of service. $66 \%$ reported to have had no opportunity to be promoted during their years of service. The characteristics of the participants are shown in Table 1 . 
TABLE 1

Characteristics of Participants

\begin{tabular}{|c|c|c|}
\hline Item & Category & Percentage \\
\hline \multirow[t]{2}{*}{ Employment category } & Academic & 47,04 \\
\hline & Administrative & 52,96 \\
\hline \multirow[t]{2}{*}{ Gender } & Male & 37,12 \\
\hline & Female & 62,88 \\
\hline \multirow[t]{4}{*}{ Language } & Afrikaans & 54,59 \\
\hline & English & 19,46 \\
\hline & Setswana & 10,81 \\
\hline & Other & 15,14 \\
\hline \multirow[t]{5}{*}{ Education } & Highest grade/standard & 21,95 \\
\hline & 3 -year qualification & 23,04 \\
\hline & 4-year qualification & 30,08 \\
\hline & Master's & 19,24 \\
\hline & Doctorate & 5,69 \\
\hline \multirow[t]{3}{*}{ Marital status } & Single/Divorced & 15,76 \\
\hline & Engaged/in relationship & 37,77 \\
\hline & Married & 44,29 \\
\hline \multirow[t]{3}{*}{ Years of service } & $0-5$ years & 31,29 \\
\hline & $5,1-10$ years & 35,19 \\
\hline & $10+$ years & 33,52 \\
\hline \multirow[t]{3}{*}{ Opportunity for promotion } & none & 65,71 \\
\hline & 1 & 23,49 \\
\hline & $2+$ & 10,80 \\
\hline \multirow[t]{2}{*}{ Studying further } & Yes & 47,28 \\
\hline & No & 52,72 \\
\hline \multirow[t]{4}{*}{ Age distribution } & $23-30$ & 19,94 \\
\hline & $31-40$ & 37,19 \\
\hline & $41-50$ & 26,21 \\
\hline & $51-60$ & 15,95 \\
\hline
\end{tabular}

\section{Measuring battery}

The Maslach Burnout Inventory - General Survey (MBI-GS) (Maslach et al., 1996) was used to measure burnout. The MBI-GS consists of 16 items and has three subscales, namely Exhaustion (Ex) (five items; e.g. "I feel used up at the end of the workday"); Cynicism (Cy) (five items; e.g. "I have become less enthusiastic about my work") and Professional Efficacy (PE) (six items; e.g. "In my opinion, I am good at my job"). These three components of the burnout construct are conceptualised in broader terms relating to the job and not just to the personal relationships that may be part of the job (Maslach, Schaufeli \& Leiter, 2001). Together the sub-scales of the MBI-GS provide a threedimensional perspective on burnout.

The items of the MBI-GS are phrased as statements about personal feelings and attitudes, which are self-scored on a sevenpoint frequency scale, ranging from 0 (never) to 6 (every day). Internal consistencies found by Leiter and Schaufeli (1996) and Schaufeli, Van Diederendonck and Van Gorp (1996) range from 0,73 (Cynicism) to 0,91 (Exhaustion). Test-retest reliabilities after one year were 0,65 (Exhaustion), 0,60 (Cynicism) and 0,67 (Professional Efficacy) (Schaufeli et al., 1996). Test-retest reliability form three months to one year ranged from $0,50-0,82$ (Leiter \& Durup, 1996). In four South African samples (Rothmann et al. 2003; Rothmann \& Jansen van Vuuren, 2002; Rothmann \& Malan, 2003; Storm \& Rothmann, 2003) alpha coefficients ranging from 0,69 (Professional Efficacy) to 0,98 (Exhaustion) were found. Storm and Rothmann (2003) confirmed the three-factor structure of the MBI-GS in the South African Police Service (SAPS), but also recommended that Item 13 should be dropped from the questionnaire. This study confirmed the structural equivalence of the MBI-GS for different race groups.

The Cognitive Weariness Scale (CWS) was developed by Van Horn et al. (in press) to measure cognitive well-being. Initially this scale consisted of seven items, but they recommended that, due to high internal consistency of items 3 and 7, item 7 be dropped in the general six-item version. The scale refers to the capacity to take up new information and loss of concentration at work, for instance, "I have trouble concentrating". It is scored on a seven-point frequency scale with 0 (a few times a year) to 6 (every day). Van Horn et al. (in press) reported a Cronbach alpha coefficient of 0,92 .

A biographical questionnaire was designed to gather gender, position, education and marital status information.

\section{Statistical analysis}

The statistical analysis was carried out with the help of the SAS program (SAS Institute, 2000) and the AMOS program (Arbuckle, 1997).

To test the factorial validity of the MBI-GS, structural equation modelling (SEM) methods were used with the maximum likelihood method of the AMOS program (Arbuckle, 1997). Hypothesised relationships are tested empirically for goodness of fit with the sample data. The $\chi^{2}$ statistic equals ( $\left.\mathrm{N}-1\right)$ Fmin, which value tends to be substantial when the model does not hold, and the sample size is large (Byrne, 2001). A large $\chi^{2}$ relative to degree of freedom indicates a need to modify the model to fit the data better. Researchers addressed the $\chi^{2}$ limitations by developing goodness-of-fit indices that take a more pragmatic approach to the evaluation process. One of the first fit statistics to address this problem was the $\chi^{2}$ /degree of freedom ratio (CMIN/DF; Wheaton, Muthèn Alwin \& Summers, 1977). These criteria, commonly referred to as "subjective/practical" indices of fit, are typically used as adjuncts to the $\chi^{2}$ statistics (Byrne, 2001). The following goodness-of-fit-indices were used as adjuncts to the $\chi^{2}$ statistics: a) The Goodness of fit Index (GFI); b) The Adjusted Goodness of Fit Index (AGFI); c) The Normed Fit Index (NFI); d) The Comparative Fit Index (CFI); e) The Tucker-Lewis Index (TLI), and f) The Root Mean Square Error of Approximation (RMSEA).

Consequently descriptive statistics (e.g. means, standard deviations, skewness and kurtosis) were used to analyse the data. Cronbach alpha coefficients, inter-item correlation coefficients and confirmatory factor analysis were used to assess the reliability and validity (i.e. internal consistency, homogeneity and unidimensionality) of the measuring instruments (Clark \& Watson, 1995). Coefficient alpha contains important information regarding the proportion of variance of the items of a scale in terms of the total variance explained by that particular scale. According to Clark and Watson (1995), the mean inter-item correlation (which is a straightforward measure of internal consistency) provides useful information in conjunction with the alpha coefficient of a scale (which is an indication of homogeneity of a scale), but cannot ensure unidimensionality of a scale. The range of inter-item correlations should also be inspected in this regard. Sufficient clustering of correlations around the mean should provide sufficient support for the unidimensionality of a scale.

Finally multivariate analysis of variance (MANOVA) was used to determine the significance of differences between burnout (exhaustion, cynicism, professional efficacy and cognitive weariness) and various biographical characteristics of the sample. MANOVA tests whether mean differences among groups on a combination of dependent variables are likely to 
have occurred by chance (Tabachnick \& Fidell, 2001). In MANOVA a new dependent variable that maximises group differences is created from the set of dependent variables. Oneway analysis is then performed on the newly created dependent variable. Wilk's Lambda was used to test the significance of the effects. Wilk's Lambda is a likelihood ratio statistic that tests the likelihood of the data under the assumption of equal population mean vectors for all groups against the likelihood under the assumption that the population mean vectors are identical to those of the sample mean vectors for the different groups. When an effect was significant in MANOVA, ANOVA was used to discover which dependent variables were affected. Because multiple ANOVAs were used, a Bonferroni type adjustment was made for inflated Type 1 error. Tukey tests were done to indicate which groups differed significantly when ANOVAs were done.

T-tests were used to determine differences between the groups in the sample. Effect sizes (Cohen, 1988; Steyn, 1999) were used in addition to statistical significance to determine the significance of relationships. Effect sizes indicate whether obtained results are important (while statistical significance may often show results which are of little practical relevance). The use of only statistical significance testing in a routine manner has been criticised and from editors of some periodicals there have been appeals to place more emphasis on effect sizes (Steyn 1999). The following formula was used to determine the practical significance of differences (d) when ttests were used (Steyn, 1999):

$\frac{\operatorname{Mean}_{A}-\operatorname{Mean}_{B}}{S D_{\text {max }}}$

Where

Mean A = Mean of the first group

Mean $\mathrm{B}=$ Mean of the second group

$\mathrm{SD}_{\max }=$ Highest standard deviation of the two groups

The following formula was used to determine the practical significance of means of more than two groups (Steyn, 1999):

$\frac{\mathrm{Mean}_{A}-\mathrm{Mean}_{B}}{\text { Root MSE }}$

Where

Mean A = Mean of the first group

Mean $\mathrm{B}=$ Mean of the second group

Root MSE $=$ Root Mean Square error

According to Cohen (1988), $0,10=d=0,50$ indicates a small effect, $0,50=d=0,80$ indicates a medium effect, and $d=0,80$ indicates a large effect.

A cut-off point of 0,50 (medium effect) (Cohen, 1988) was set for the practical significance of differences between group means.

\section{RESULTS}

Structural equation modelling (SEM) methods, as implemented by AMOS (Arbuckle, 1997), were used to test the factorial models for the MBI-GS. Data analysis was conducted in two consecutive steps. Firstly, a quick overview of the model fit was done by looking at the overall $\chi^{2}$ value, together with its degrees of freedom and probability value. Several goodnessof-fit statistics (GFI, AGFI, PGFI, NFI, TLI, CFI and RMSEA) were used for the global assessment of the model fits. Secondly, given findings of a poor-fitting initially hypothesised model, exploratory analysis was done. Possible misspecifications, as suggested by the so-called modification indices, were looked for in order to fit a revised, respecified model to the data.

\section{Hypothesised model}

The aim of this study was to verify an adapted model of burnout consisting of a three-factor model (as confirmed in research) with Cognitive Weariness as a fourth factor. Three default models using the total population were tested: A one-factor model of burnout; a four-factor model of burnout (with Cognitive Weariness as fourth factor); and a three-factor model of burnout with Cognitive Weariness loading on Exhaustion. Table 2 presents fit statistics for the default models.

TABLE 2

The Goodness-of-fit Statistics for the Hypothesised ONEFactor, Three-Factor AND Four-Factor MBI-GS Models

\begin{tabular}{lcccccccc}
\hline Default Model & $\chi^{2}$ & $\chi^{2} / \mathrm{df}$ & GFI & AGFI & NFI & TLI & CFI & RMSEA \\
\hline $\begin{array}{l}\text { Model 1 } \\
\text { (1 factor) }\end{array}$ & 1456,77 & 4,50 & 0,72 & 0,68 & 0,62 & 0,65 & 0,68 & 0,10 \\
$\begin{array}{l}\text { Model 2 } \\
\text { (3 factor) }\end{array}$ & 595,89 & 2,92 & 0,87 & 0,84 & 0,80 & 0,84 & 0,85 & 0,07 \\
$\begin{array}{l}\text { Model 3 } \\
(4 \text { factor })\end{array}$ & 557,19 & 2,74 & 0,88 & 0,85 & 0,81 & 0,85 & 0,87 & 0,07 \\
\hline
\end{tabular}

The first model (Default Model 1) tested was a one-factor model of the MBI-GS, but very poor overall fit was obtained, as indicated by the statistically significant $\chi^{2}$ value of 1456,77 ( $d f=$ $323,72 ; p=0,00)$. All the other fit indices confirmed an extremely poor fit with the data.

The second model (Default Model 2) consisted of three factors, namely Weariness (consisting of Exhaustion and Cognitive Weariness), Cynicism and Professional Efficacy. Again a rather poor overall fit was obtained, as indicated by the statistically significant $\chi^{2}$ value of $557,19(d f=204,07 ; p=0,00)$ (Golembiewski \& Munzenrider, 1988; Meier, 1984). All the other fit indices confirmed a poor fit with the data.

The full hypothesised four-factor model (Exhaustion; Cynicism; Professional Efficacy; Cognitive Weariness) consisting of 22 items (Default Model 3) was consequently tested. The statistically significant $\chi^{2}$ value of $557,19(d f=203$; $p=0,00)$ still revealed a very poor overall fit with the originally hypothesized four-factor model, but it is better than the $\chi^{2}$ values of the one-factor and three-factor models. All other indices indicated a poor fit between the hypothesised model and the data obtained. From a practical perspective, a large $\chi^{2}$ value relative to the degrees of freedom, together with NFI, TLI and CFI values lower than 0,95 and a RMSEA value higher than 508, are indicative of a failure to confirm the hypothesised model and requires a need to modify the model to better fit the data. In order to determine a model that better represents the sample data, modification indices (MI) were examined to identify possible areas of misfit. Table 3 presents fit statistics for the subsequent changes of the 4 -factor model.

Looking at the regression weights, two parameters which represent the cross-loading of Item 13 and 27 (Model 1) indicated a considerably lower regression weight compared with the other MBI items. Item 16 (Model 2) and Item 4 (Model 3) were also problematic. In the next step considerable constrained error co-variation was detected between error 14 and error 15 (items 14 and 15) and error 11 and error 12 (items 11 and 12) (Model 4). These parameters could account for the substantial misspecification of the hypothesised factor loading. 
TABLe 3

The Goodness-of-fit StATISTICS For THE Hypothesised FOUR-FACTOR MBI-GS MODEL

\begin{tabular}{lcccccccc}
\hline Model & $\chi^{2}$ & $\chi^{2} / \mathrm{df}$ & GFI & AGFI & NFI & TLI & CFI RMSEA \\
\hline Model 1 & 459,16 & 2,80 & 0,89 & 0,86 & 0,84 & 0,87 & 0,89 & 0,07 \\
Model 2 & 361,77 & 2,48 & 0,91 & 0,88 & 0,86 & 0,89 & 0,91 & 0,06 \\
Model 3 & 313,77 & 2,43 & 0,92 & 0,89 & 0,86 & 0,90 & 0,91 & 0,06 \\
Model 4 & 298,87 & 2,35 & 0,92 & 0,89 & 0,87 & 0,90 & 0,92 & 0,06 \\
\hline
\end{tabular}

\section{Post-hoc analysis}

Based on the regression weights and standardised residual covariances, the four-factor model was re-estimated with Item 13 and Item 27 removed (see Model 1). Consequently Item 16 (see Model 2) and Item 4 (see Model 3) were removed. Errors of two item pairs, namely Items 14 and 15 (errors 14 and 15) and Items 11 and 12 (errors 11 and 12) were allowed to correlate. The final model of the MBI-GS structure (Model 4) was based on 18 of the original 22 items and included correlated errors between items 14 and 15, as well as items 11 and 12. After testing each of the resulting models, based on the adjustments as described, the $\chi^{2}$ value and other indices appeared to have improved compared to those of the original four-factor model.

The results of the final model (Model 4) are shown in Table 3. Although the $\chi^{2}$ value of $298,87(d f=127 ; p=0,00)$ is still high, it is considerably lower than that of the hypothesised model. The other fit statistics indicate an acceptable fit for the re-specified model.

The descriptive statistics, alpha coefficients and inter-item correlations of the four factors of the MBI-GS are given in Table 4 .

TABLE 4

Descriptive Statistics, Alpha Coefficients and Inter-Item Correlations OF THE MBI-GS

\begin{tabular}{lcccccc}
\hline Dimension & Mean & SD & Skewness & Kurtosis & $r$ (Mean) & $\alpha$ \\
\hline Exhaustion & 11,32 & 6,37 & 0,13 & $-0,90$ & 0,58 & 0,85 \\
Cynicism & 8,03 & 5,46 & 0,41 & $-0,20$ & 0,37 & 0,70 \\
Professional Efficacy & 23,34 & 5,03 & $-0,76$ & 0,25 & 0,28 & 0,66 \\
Cognitive Weariness & 9,50 & 6,05 & 0,47 & $-0,38$ & 0,39 & 0,76 \\
\hline
\end{tabular}

The results in Table 4 indicate that the scores on the four dimensions of the adapted model of burnout are normally distributed. It is evident that with regard to internal consistency three dimensions, namely Exhaustion, Cynicism and Cognitive Weariness, seem to demonstrate acceptable coefficient alphas above the 0,70 guideline provided by Nunnally and Bernstein (1994). Even though the alpha coefficient for Professional Efficacy $(0,66)$ is below the guideline of 0,70 , it is consistent with the findings of Rothmann et al. (2003) in their study of burnout (MBI-GS) and job stress in local government, and Storm and Rothmann (2003) in the South African Police Service. Furthermore, acceptable levels of inter-item correlations have been obtained for three factors (Cynicism, Professional Efficacy and Cognitive Weariness) consistent with the guideline of $0,15 \leq r \leq 0,50$ suggested by Clark and Watson (1995). Exhaustion $(0,58)$ had an inter-item correlation higher than the guideline. A measure of internal consistency (Cronbach alpha) is not an indication of the homogeneity or unidimensionality of a scale, but it is necessary to take the range of inter-item correlations into consideration when considering homogeneity and unidimensionality (Clark \& Watson, 1995). In terms of these guidelines, the MBI-GS seems to satisfy the requirements of homogeneity (acceptable internal consistencies) and unidimensionality (acceptable clustering of inter-item correlations around the mean).

These results provide support for Hypothesis 1.

Next, MANOVA and ANOVA analyses followed to determine the relationship between burnout and various biographical characteristics, such as age, gender, language and, age, years experience at institution and job category. Biographical characteristics were first analysed for statistical significance using Wilk's' Lambda statistics. The results are shown in Table 5 .

TABle 5

MANOVAS - DifFERENCES IN BURNOUT LEVELS BASED on Biographical Characteristics

\begin{tabular}{lccccc}
\hline Variable & Value & $\boldsymbol{F}$ & $\boldsymbol{d f}$ & Den DF & $\boldsymbol{p}$ \\
\hline Language & 0,87 & 6,50 & 8 & 706 & $0,00^{*}$ \\
Age & 0,98 & 0,78 & 8 & 688 & 0,62 \\
Years experience & 0,94 & 2,64 & 8 & 702 & $0,00^{*}$ \\
\hline
\end{tabular}

* Statistically significant difference: $p \leq 0,01$

In an analysis of Wilk's Lambda values, no statistically significant differences $(p<0,01)$ regarding burnout levels could be found between different age groups. However, statistically significant differences $(p \leq 0,01)$ were found for different language groups and categories of different years of experience at the institution. The relationship between burnout and those biographical characteristics that showed a statistically significant difference was further analysed to determine practical significance using ANOVA, followed by Tukey HSD tests.

The ANOVAs of differences in burnout levels of the different language groups are given in Table 6 .

TABLE 6

ANOVAS - DifFerences In BURNOUT LeVels OF Different Language Groups

\begin{tabular}{lccccc}
\hline Dimension & Afrikaans & English & Indigenous & $\boldsymbol{p}$ & Root MSE \\
\hline Exhaustion & $12,31^{\mathrm{b}}$ & $12,61^{\mathrm{b}}$ & 8,18 & $0,00^{*}$ & 6,09 \\
Cynicism & 8,39 & 8,85 & 6,78 & 0,03 & 5,44 \\
Professional efficacy & 23,05 & 23,38 & 23,82 & 0,54 & 5,06 \\
Cognitive Weariness & $10,94^{\mathrm{c}}$ & $9,76^{\mathrm{b}}$ & 6,36 & $0,00^{*}$ & 5,73 \\
\hline
\end{tabular}

* Statistically significant difference: $p \leq 0,01$

a Practically significant differences from language group (in row) where $\mathrm{b}$ (medium effect, $d \geq 0,5$ ) or c (large effect, $d \geq 0,8$ ) are indicated

According to Table 6, Afrikaans- and English-speaking language groups scored significantly higher on Exhaustion than the indigenous language-speaking groups (practically significant, medium effect). Afrikaans- (practically significant difference, large effect) and English-speaking (practically significant difference, medium effect) language groups also scored significantly higher than indigenous language-speaking groups in terms of Cognitive Weariness levels.

Table 7 shows the ANOVAs of differences in burnout levels for different categories of years of experience at the institution. 
TABLE 7

ANOVAS - DIFFERENCES IN BURNOUT LEVELS OF Years of Experience Categories

\begin{tabular}{lccccc}
\hline Dimension & $\mathbf{0 - 5}$ years & $\mathbf{5 , 1 - 1 0}$ years & $\mathbf{1 0 , 1 - 4 4}$ years & $\boldsymbol{p}$ & Root MSE \\
\hline Exhaustion & 9,54 & 10,96 & $12,87 \mathrm{~b}$ & $0,00 *$ & 6,23 \\
Cynicism & 6,40 & 7,74 & $9,03 \mathrm{a}$ & $0,01 *$ & 5,49 \\
Professional efficacy & 24,90 & 23,06 & 22,99 & 0,06 & 5,03 \\
Cognitive Weariness & 8,13 & 9,07 & $11,13 \mathrm{~b}$ & $0,00 *$ & 6,00 \\
\hline
\end{tabular}

* Statistically significant difference: $p \leq 0,01$

a Practically significant differences from group (in row) where b (medium effect, $d \geq 0,5$ ) or c (large effect, $d \geq 0,8$ ) are indicated

Table 7 indicates that people with more than 10 years' experience at the institution scored practically significantly higher on the Exhaustion (medium effect), Cynicism and Cognitive Weariness (medium effect) dimensions of burnout in comparison with those with $0-5$ years experience. This is contrary to research that has shown that burnout is negatively related to work experience, and that younger employees are more prone to burnout (Cherniss, 1980; Künzel \& Schulte, 1986; Maslach, Jackson \& Leiter, 1996), but might be in line with the findings of Zijlstra and De Vries (2001) that older, more experienced, single workers who experienced a high workload were significantly more at risk compared to younger, less experienced, married workers with a low workload.

No statistically significant differences could be found regarding the burnout levels of different gender groups.

The results in Tables 5-7 provide partial supporting evidence for the acceptance of hypothesis 2, which statedprojected that significant differences based on the biographical characteristics of gender, job characteristics, age, language and years of experience at the institution will exist. In contrast with the hypothesis, higher levels of burnout were found among workers with more years of experience at the institution and significant differences were found between different language groups. Also unexpectedly, no differences were found between genders. It can thus be concluded that, as hypothesised, differences based on biographical characteristics were found, but they reflected quite a different picture from that expected on the basis of the literature.

\section{DISCUSSION}

The aim of this study was to determine the factorial validity and internal consistency validate of an adapted four-factor model of the the MBI-GS and Cognitive Weariness Scale for employees at a higher education institution in South Africa and to determine differences between genders, different language groups, employees in different age groups and employees with different years of experience at the institution.

The psychometric soundness of an adapted version of the the MBI-GS and CWS was tested, i.e. the construct validity and internal consistency. Reliability analysis confirmed sufficient internal consistency of the subscales. The results obtained using the structural equation modelling approach supported a four-factor structure for the adapted MBI-GS and Cognitive Weariness Scale with Exhaustion, Cynicism, Professional Efficacy and Cognitive Weariness as factors. These findings are is a first in South African research on burnout, and consistent with the findings of Van Horn et al. (in press). However, based on both conceptual and empirical grounds, items 4, 13 and 16 were eliminated from the original MBI-GS, resulting in a 13 item scale. It seems as if problems with item 13 ("I just want to do my job and not be bothered") might be caused by the ambivalent nature of the item, as confirmed by previous research (Rothmann et al., 2003; Rothmann \& Jansen van Vuuren, 2002; Rothmann \& Malan, 2003; Schutte et al. 2000). Even though item 4 ("Working all day is really a strain for me") and item 16 ("At my work I feel confident that I am effective at getting things done") also contributed to unwanted variance in the model, no theoretical premise could be found for its omission in the post hoc analysis. Possibly, this could be attributed to small sample size $(N=372)$ in subsequent analysis, or alternatively to the fact that these items were perceived as not relevant in the work reality, due to the fact that the population in general did not report excessively high levels of burnout. These two questions are specifically related to aspects of overload which do not seem to be a major stressor among the population of this institution, and thus could result in participants' disregard of the relevance of these specific questions in their work situation, subsequently contributing to the unwanted variance in the model. The ambivalent content of these two items could also play a role here. Even though the elimination of items 4 and 16 increased model fit, their omission in post hoc analysis can be explained on conceptual grounds and should be validated in future larger replicated studies in higher education institutions.

The fourth burnout dimension that was added in this study was the six-item Cognitive Weariness scale as compiled by Van Horn et al. (in press). Item 27 ("I have problems processing new information"), which forms part of the six-item Cognitive Weariness Scalet scale, proved to be problematic and was subsequently eliminated on conceptual and empirical grounds. Its omission from post hoc analysis might also be explained by the ambivalence of this particular item. Participants might relate this item to a study and not to a work scenario and misinterpret its content as related to the processing of study material which might not be relevant for the $53 \%$ of the population not currently involved in improving their qualifications. However, the omission of this item should be validated in future research.

Furthermore, error terms within the subscales were allowed to correlate in order to improve model fit. Although correlated error terms may be derived from specific characteristics of either the respondents or the items of a survey, they represent systematic rather than random measurement error in item responses. This could indicate, for example, a small omitted factor or, which is more likely the case in the current study, could be reflective of respondent characteristics contributing to the bias of an instrument by means of randomly responding to items without really reading the items, social desirability (Aish \& Jöreskog, 1990) as well as a high degree of item content overlap, i.e. different wording of an item, but essentially meaning the same thing (Byrne, 2001). From a technical, psychometric point of view the MBI-GS is a good instrument. From a clinical psychological perspective the MBI-GS does not cover the whole range of symptoms that are observed among employees with severe burnout (Schaufeli, 2003). Most notably cognitive impairment and, distress symptoms (neurasthenic distress) are excluded while and reduced professional efficacy does not seem to play an important role. This research seems to prove that the original model of the MBI-GS is in need of re-specification and that additional aspects (e.g. cognitive weariness and, neurasthenic symptoms and professional efficacy) need to be considered for future inclusion.

Regarding the differences in burnout levels based on biographical characteristics, it was found that Afrikaans (55\% of the population) and English (19\% of the population) language groups experience significantly higher levels of Exhaustion and Cognitive Weariness than the indigenous language groups (26\% of the population). Employees with more than 10 years experience at the institution $(34 \%$ of the 
population) also experience significantly (practically and statistically significant differences) higher levels of Exhaustion, Cynicism and Cognitive Weariness. This is in contrast with research that has shown that younger employees are more prone to burnout and that burnout is negatively related to work experience (Cherniss, 1980; Künzel \& Schulte, 1986; Maslach et al., 1996), but might be in line with the findings of Zijlstra and De Vries (2001) that older, more experienced, single workers who experienced a high workload were significantly more at risk compared to younger, less experienced, married workers with a low workload.

These observations might be understood if the recent history of this institution is taken into account. During the past eight years the student population has been transformed from predominantly white to predominantly black students. This led to the change of the official language used at the institution from Afrikaans to English. During the same time (in adherence to the equity legislation passed by the postapartheid government of South Africa), a decision was made to appoint only designated groups (i.e. black, Indian, Coloured and white female applicants, in order of preference) in vacant positions to ensure that the staff component reflects the demographics of the area (Vaal Triangle). Consequently, the staff component was changed from predominantly white to being demographically representative, and the management of the institution was also transformed.

As a result of these fast-paced and radical interventions, most of the employees with more than 10 years' experience are white and in the Afrikaans- (55\%) and English-speaking (19\%) language groups. The Afrikaans speaking, white employees additionally had to adjust to communicate/educate second language-speaking students (indigenous languages) in, for them also, a second language (English). Both the Afrikaans and English language groups who have been employed at the institution for more than 10 years were are also subjected to radical changes with regard to the culture of their clients (the students) and their co-workers. Another source of change might be the total transformation of the top management of the institution and its secondary impact on the governance, culture and climate of the organisation. Adjusting to these changes in a relatively short period of time might have resulted in elevated levels of Exhaustion, Cognitive Weariness and Cynicism among the Afrikaans- and English-language groups in comparison with the indigenous language-speaking (26\%) staff component, who in the population also predominantly represent those with 0-5 years of experience. Of concern is the fact that those employees adversely affected by Exhaustion, Cognitive Weariness and Cynicism represent, based on language groups, $74 \%$, and based on years of experience, $34 \%$ of the population - figures that cannot be ignored if employee wellness is a priority in an organisation.

In conclusion, a this study could serve as a standard regarding burnout levels of the total population in a higher education institution. Added to the previously accepted three-factor structure of burnout, an adapted four-factor structure of burnout is largely confirmed, as well as the internal consistency of Exhaustion, Cynicism, Professional Efficacy and Cognitive Weariness. Based on the results obtained in the study, it would seem as if the adapted version of the MBI-GS in combination with the Cognitive Weariness Scale could be regarded as a suitable instrument for measuring burnout in higher education institutions in South Africa. The higher levels of Exhaustion, Cognitive Weariness and Cynicism that were observed among Afrikaans- and English-language groups, as well as among those with more than 10 years' experience at the institution, are also an alarming aspect that certainly justifies further research, especially in institutions that are marked by radical transformation in a short period of time.
A limitation of this study is its reliance solely on self-report measures. According to Schaufeli, Enzmann and Girault (1993) the exclusive use of self-report measures in validation studies increases the likelihood that at least part of the shared variances between measures can be attributed to method variance. Another limitation is the size of the sample, which has significant limitations in terms of the generalisation of the findings applied to the total study population. Future studies could benefit hugely in terms of a stratified random-sample design which would ensure sufficient representation of the different groups in the total population. Also, in terms of the research design, future studies should focus on longitudinal designs where inferences in terms of cause and effect could be made. Future studies conducted should consider extending the sample to include employees of all the higher education institutions in South Africa in order to standardise an adapted version of the MBI-GS for employees of higher education institutions in South Africa.

\section{RECOMMENDATIONS}

According to the results obtained in this study, the use of the MBI-GS combined with the Cognitive Weariness Scale is recommended to assess burnout in higher education institutions in South Africa. However, item 13 should be omitted from the MBI-GS. The additional omission of items 4 and 16 from the MBI-GS and item 27 from the Cognitive Weariness Scale (item 6 in the original version of CWS) should be validated in future research.

In order to fully understand the effect of different biographic characteristics on burnout and cognitive weariness, especially in institutions undergoing radical transformation on different levels simultaneously, it is recommended that future studies with regard to higher education institutions in South Africa be expanded to measure the secondary impact that the negative residue of burnout might have on affected employees, students and co-workers. Another informative investigation could include the effect of burnout and cognitive weariness on the psychological contract and organisational commitment of the individual.

It is suggested that future research focus on the MBI-GS and Cognitive Weariness Scale in other higher education institutions in South Africa to verify the current findings. Other occupational settings should also be investigated in a similar manner in order to verify the reliability and validity of the MBIGS and Cognitive Weariness Scale. It is also important to determine norm levels for other occupations in South Africa. It is recommended that larger samples with a more powerful sampling method be utilised to enable generalisation of the findings to other similar groups. It might also be necessary to translate the adapted version of the the MBI-GS and Cognitive Weariness Scale into other languages used in South Africa.

\section{AUTHOR NOTE}

The material described in this article is based upon work supported by the National Research Foundation under Grant number 2053344.

\section{REFERENCES}

Aiken, L.H., Clarke, S.P., Sloane, D.M., Sochalski, J. \& Silber, J.H. (2002) Hospital nurse staffing and patient mortality, nurse burnout and job dissatisfaction. Journal of the American Medical Association, 288, 1987-1993.

Aish, A.M. \& Jöreskog, K.G. (1990). A panel model for political efficacy responsiveness: An application of LISREL 7 with weighted least squares. Quality and Quantity, 19, 716-723. 
Alexy, B.B. (1991). Factors associated with participation or nonparticipation in a workplace wellness center. Research in Nursing and Health, 14 (1), 33-40.

Arbuckle, J.L. (1997). Amos user's guide version 4.0. Chicago: Smallwaters Corporation.

Bakker, A., Demerouti, E. \& Schaufeli, W.B. (2002). Validation of the Maslach Burnout Inventory - General Survey: An internet study. Anxiety, Stress and Coping, 15, 245-260.

Barling, J. (1999). Changing employment relations: Empirical data, social perspectives and policy options. In D.B. Knight $\&$ A. Joseph (Eds.), Restructuring societies: Insights form the social sciences (pp.59-82). Ottawa, Canada: Carlton University Press.

Blackmore, J. (2001). Universities in crisis? Knowledge economics, emancipatory pedagogies, and the critical intellectual. Educational Theory, 51, 353-370.

Blaise Jr., O.N. (1996). A wellness prescription for superintendents. The School Administrator, 53(3), 34-39.

Boles, J.S., Dean, D.H., Ricks, J.M., Short, J.C., \& Wang, G. (2000). The dimensionality of the Maslach Burnout Inventory across small business owners and educators. Journal of Vocational Behavior, 56, 12-34.

Brill, P.L. (1984). The need for an operational definition of burnout. Family and Community Health, 6, 12-24.

Broadbent, D.E., Cooper, P.F., FitzGerald, P. \& Parkes, K.R. (1982). The Cognitive Failures Questionnaire (CFQ) and its correlates. British Journal of Clinical Psychology, 21, 1-16.

Brown, P. (1999). Globalization and the political economy of high skills. Journal of Education and Work, 12, 233-251.

Browne, M.W. \& Cudeck, R. (1993). Alternative ways of assessing model fit. In K.A. Bollen \& J.S. Long (Eds.), Testing structural equation models (pp. 136-162). London: Sage.

Burns, N. \& Grové, S.K. (1993). The practice of nursing research, conduct, critique, and utilization (2nd ed.). Philadelphia: W.B. Saunders.

Byrne, B.M. (1991). The Maslach Burnout Inventory: Validating factorial structure and invariance across intermediate secondary and university educators. Multivariate Behavioral Research, 26, 583-605.

Byrne, B.M. (2001). Structural equation modelling with AMOS: Basic concepts, applications and programming. Mahwah, NJ: Erlbaum.

Cash, D. (1988). A study of the relationship of demographics, personality and role stress to burnout in intensive care unit nurses. Dissertation Abstracts International, 49, 2585 A.

Cherniss, C. (1980). Staff burnout. Beverly Hills, CA: Sage.

Clark, L.A. \& Watson, D. (1995). Constructing validity: Basic issues in objective scale development. Psychological Assessment, 7, 309-319.

Cohen, J. (1988). Statistical power analysis for behavioral sciences (Rev. ed.). Orlando, FL: Academic Press.

Cordes, C.L. \& Dougherty, T.W. (1993). A review and an integration of research on job burnout. Academy of Management Review, 18, 621-656.

Cross, M. Mungadi, R. \& Rouhani, S. (2002). From policy to practice: Curriculum reform in South African education. Comparative Education, 38, 171-187.

Enzmann, D. Schaufeli, W.B. \& Girault, N. (1995). The validity of the Maslach Burnout Inventory in three national samples. In L. Bennett, D. Miller \& M. Ross (Eds.), Health workers and AIDS: Research, interventions and current issues (pp. 131-150). Chur: Harwoord.

Evans, B.K. \& Fisher, D.G. (1993). The nature of burnout: A study of the three factor model of burnout in human services and non-human services samples. Journal of Occupational and Organizational Psychology, 66, 29-38.

Gilbert, A.D. (2000). The idea of a university beyond 2000. Policy, 16, 31-36.

Glasgow, R.E. Terborg, J.R., Hollis, J.F., Severson, H.H. \& Boles, S.M. (1995). Take heart: Results from the initial phase of a work-site wellness program. American Journal of Public Health, 85, 209-215.
Goldberg, D. (1972). The detection of mental illness by questionnaire. London: Oxford University Press.

Goldstein, A. (1992). Stress in the superintendancy: School leaders confront the daunting pressures of the job. The School Administrator, 49(9), 8-13.

Golembiewski, R.T. \& Munzenrider, R.F. (1988). Phases of burnout: Development in concepts and applications. New York: Praeger.

Hoogduin, C., Schaap, C., Methorst, G., Peters van Neyenhof, C. \& Van de Griendt, J. (2001). Burnout: Klinisch beeld en diagnostiek [Burnout: Clinical description and diagnosis]. In C.A.L. Hoogduin, W.B. Schaufeli, C.P.D.R. Schaap \& A.B. Bakker (Eds.), Behandelingsstrategiën bij burnout (pp. 13-20). Houten: Bohn Strafleu VanLoghum.

Hoyle, R.H. (1995). The structural equation modeling approach: Basic concepts and fundamental issues. In R.H. Hoyle (Ed.), Structural equation modeling: Concepts, issues and applications (pp. 1-15). Thousand Oaks, CA: Sage.

Hu, L.T. \& Bentler, P.M. (1999). Cutoff criteria indexes in covariance structure analysis: Conventional criteria versus new alternatives. Structural Equation Modeling: A Multidisciplinary Journal, 6, 1-55.

Jöreskog, K.G. \& Sörbom, D. (1986). LISREL user guide version VI (4th ed.). Moorseville, IL: Scientific Software International.

Jöreskog, K.G. \& Sörbom, D. (1993). LISREL 8: Structural equation modeling with the SIMPLIS command language. Hillside, NJ: Lawrence Erlbaum Associates.

Kistan, C. (1999). Quality assurance in South Africa. Quality Assurance in Education, 7, 125-134.

Koeske, G.F. \& Koeske, R.D. (1993). Construct validity of the Maslach Burnout Inventory: A critical review and conceptualization. Journal of Applied Behavioral Science, 25, 131-132.

Kraak, A. (2000). Changing modes: New knowledge production and its implications for higher education in South Africa. Parow, South Africa: CTP Book Printers.

Künzel, R. \& Schulte, D. (1986). Burnout and reality shock among clinical psychologists. Zeitschrift for Klinische Psychologie, Forschung und Praxis, 15, 303-320.

Landsbergis, P. (2003). The changing organization of work and the safety and health of working people: A commentary. Journal of Occupational and Environmental Medicine, 45, 61-72.

Leiter, M.P. \& Durup, J. (1996). Work, home, and in-between: A longitudinal study of spill-over. Journal of Applied Behavioral Science, 32, 29-47.

Leiter, M.P. \& Schaufeli, W.B. (1996). Consistency of the burnout construct across occupations. Anxiety, Stress and Coping, 9, 229-243.

Levert, T., Lucas M. \& Ortlepp, K. (2000). Burnout in psychiatric nurses: Contributions of the work environment and a Sense of Coherence. South African Journal of Psychology, 30, 36-43.

Lomas, L. (1997). The decline of liberal education and the emergence of a new model of education and training. Education and training, 39, 111-115.

MacCallum, R.C., Browne, M.W. \& Sugawara, H.M. (1996). Power analysis and determination of sample size for covariance structure modeling. Psychological Methods, 1, 130-149.

Marais, H.C., Grobbelaar, J.W. \& Potgieter, K.M. (1997). Critical issues in South African higher education reform. Pretoria, South Africa: SAUVCA Publication Series.

Marsh, H.W., Balla, J.R. \& Hau, K.T. (1996). An evaluation of Incremental Fit Indices: A clarification of mathematical and empirical properties. In G.A. Marcoulides \& R.E. Schumacker (Eds.), Advanced structural modeling: Issues and techniques (pp. 315-353). Mahwah, NJ: Erlbaum.

Martin, P. (1997). The sickening mind: Brain, behaviour, immunity and disease. London: Harper Collins.

Maslach, C. (1993). Burnout: A multidimensional perspective. In W.B. Schaufeli, C. Maslach \& T. Marek (Eds.). Professional burnout: Recent developments in theory and research (pp. 1932). Washington, DC: Taylor \& Francis. 
Maslach, C. \& Jackson, S.E. (1981). The measurement of experienced burnout. Journal of Occupational Behavior, 2, 99-113.

Maslach, C. \& Jackson, S.E. (1986). The Maslach Burnout Inventory (2 $2^{\text {nd }}$ ed.). Palo Alto, CA: Consulting Psychologists Press.

Maslach, C., Jackson, S.E. \& Leiter, M.P. (1996). Maslach Burnout Inventory: Manual (3rd ed.). Palo Alto, CA: Consulting Psychologists Press.

Maslach, C., Schaufeli, W.B. \& Leiter, M.P. (2001). Job burnout. Annual Review of Psychology, 52, 397-422.

Meier, S.T. (1984). The construct validity of burnout. Journal of Occupational Psychology, 57, 211-219.

Meléndeze, W.A. \& De Guzmán, R.M. (1983). Burnout: The new academic disease. ASHE - ERIC Higher Education Research Report No. 9. Washington, DC: Association for the Study of Higher Education.

Merllié, D. \& Paoli, P. (2001). Ten years of working conditions in the European Union. Dublin: European Foundation for the Improvement of Living and Working Conditions.

Mulaik, S.A., James, L.R., Van Altine, J., Bennet, N., Lind, S. \& Stillwell, C.D. (1989). Evaluation of goodness-of-fit indices for structural equation models. Psychological Bulletin, 105, 430-445.

Nunnally, J.C. \& Bernstein, I.H. (1994). Psychometric theory (3rd ed.). New York: McGraw-Hill.

Posig, M. \& Kickul, J. (2003). Extending our understanding of burnout: Test of an integrated model in non-service occupations. Journal of Occupational Health Psychology, 8(1), 1076-8998.

Robertson, D. (1998). The emerging political economy of higher education. Studies in Higher Education, 23, 221-228.

Rosse, J.G., Boss, R.W., Johnson, A.E. \& Crown, D.F. (1991). Conceptualizing the role of self-esteem in the burnout process. Group and Organization Studies, 16, 197-204.

Rothmann, S. (2003). Burnout and engagement: A South African perspective. SA Journal of Industrial Psychology, 29 (4), 16-25.

Rothmann, S., Jackson, L.T.B. \& Kruger, M.M. (2003). Burnout and job stress in a local government: The moderating effect of sense of coherence. SA Journal of Industrial Psychology, 29 (4), 52-60.

Rothmann, S. \& Jansen van Vuuren, J.A. (2002, March). Sense of coherence, self-efficacy, locus of control, coping and burnout of senior managers in a manufacturing industry. Poster session presented at the 1st South African Burnout Conference, Potchefstroom.

Rothmann, S. \& Malan, H. (2003). Koherensiesin, selfdoeltreffendheid, lokus van beheer en uitbranding by maatskaplike werkers [Sense of coherence, self-efficacy, locus of control and burnout of social workers]. SA Journal of Industrial Psychology, 29(4), 43 -51.

Rowley, R. (2000). Is higher education ready for knowledge management? The International Journal of Educational Management, 14, 325-333.

Sackney, L., Noonan, B. \& Miller, C.M. (2000). Leadership for educator wellness: An exploratory study. International Journal of Leadership in Education, 3 (1), 41-56.

Salanova, M. \& Schaufeli, W.B. (2000). Exposure to technology and its relationship to burnout. Behaviour and Information Technology, 19, 385-392.

SAS Institute (2000). The SAS System for Windows: Release 8.01. Cary, NC: SAS Institute Inc.

Schaufeli, W.B. (2003). Past performance and future perspectives of burnout research. South African Journal of Industrial Psychology, 29(4), 1-15.

Schaufeli, W.B., Bakker, A., Hoogduin, C.A.L. Schaap, C. \& Kladler, A., (2001). On the clinical validity of the Maslach Burnout Inventory and the Burnout Measure. Psychology and Health, 16, 565-582.

Schaufeli, W.B. \& Enzmann, D. (1998). The burnout companion to study and practice: A critical analysis. London: Taylor \& Francis.
Schaufeli, W.B., Enzmann, D. \& Girault, N. (1993). Measurement of burnout: A review. In W.B. Schaufeli, C. Maslach and T. Marek (Eds.), Professional burnout: Recent developments in theory and research (pp. 199-215). Washington, DC: Taylor \& Francis.

Schaufeli, W.B., Leiter, M.P. \& Kalimo, R. (1995, September). The General Burnout Questionnaire: Gross-national development and validation. Paper presented at the APA/NIOSH Congress Work, Stress and Health, Creating Healthier Workplaces, Washington, DC.

Schaufeli, W.B., Leiter, M.P., Maslach, C. \& Jackson, S.E. (1996). Maslach Burnout Inventory - General Survey. In C. Maslach, S.E. Jackson \& M.P. Leiter, The Maslach Burnout Inventory Test Manual (3rd ed.). Palo Alto, CA: Consulting Psychologists Press.

Schaufeli, W.B., Martinez, I., Pinto, A.M., Salanova, M. \& Bakker A.B. (2002). Burnout and engagement in university students: A cross-national study. Journal of Cross-Cultural Psychology, 33, 464-481.

Schaufeli, W.B. \& Van Dierendonck, D. (2000). Handleiding van de Utrechtse Burnout School (UBOS) [Manual of the Utrecht Burnout Scale]. Lisse: Swets \& Zeitlinger.

Schaufeli, W.B., Van Diederendonck, D. \& Van Gorp, K. (1996). Burnout and reciprocity: Towards a dual-level social exchange model. Work and Stress, 10, 225-237.

Schnacke, S.B., Martray, C.R. \& Heck, J.C. (1994). Educational reform: Implications of change on wellness. Thresholds in Education, 20 (1), 17-19.

Schutte, N., Toppinen, S., Kalimo, R. \& Schaufeli, W.B. (2000). The factorial validity of the Maslach Burnout Inventory General Survey (MBI-GS) across occupational groups and nations. Journal of Occupational and Organisational Psychology, 73 (1), 53-66.

Seldin, P. (1991). Reducing stress on campus. Planning for Higher Education, 9 (4), 14-20.

Shortlidge, R.L. (Jr.) (2003). University training for Gramsevaks in India: An example of recurrent education in a low-income country. Center for Human Research Ohio State University.

Steyn, H.S. (1999). Praktiese betekenisvolheid: Die gebruik van effek-groottes. Wetenskaplike bydraes, Reeks B: Natuurwetenskappe Nr. 117. [Practical significance: Use of effect sizes. Scientific contributions, Series B, Natural Sciences, No. 117]. Potchefstroom, South Africa: Potchefstroom University for Christian Higher Education, Statistical Consultation Services.

Storm, K. \& Rothmann, S. (2003). A psychometric analysis of the Maslach Burnout Inventory - General Survey in the South African Police Service. South African Journal of Psychology, 33, 219-226.

Storm, K. \& Rothmann, S. (2003, June). A psychometric analysis of the Maslach Burnout Inventory in the South African Police Service. Paper presented at the $6^{\text {th }}$ Annual Conference of the Society of Industrial and Organisation Psychology of South Africa, Johannesburg.

Tabachnick, B.G. \& Fidell, L.S. (2001). Using multivariate statistics (4th ed). Boston, MA: Allyn \& Bacon.

Taris, T.W., Schreurs, P.J.G. \& Schaufeli, W.B. (1999). Construct validity of the Maslach Burnout Inventory - General Survey: A two-sample examination of its factor structure and correlates. Work and Stress, 13, 223-237.

Taris, T., Stoffelsen, J., Bakker, A., Schaufeli, W. \& Van Dierendonck,D. (2002). Verschillen in burnout risico tussen functies en individuen: Wat is de rol van regelmogelijkheden? [Differences in burnout risks between jobs and individuals: What is the role of autonomy?] Gedrag en Gezondheid, 30, 17-29.

Tucker, L.R. \& Lewis, C. (1973). A reliability coefficient for maximum likelihood factor analysis. Psychometrica, 38, 1-10

Turner, N., Barling, J. \& Zacharatos, A. (2002). Positive psychology at work. In C.R. Snyder \& S.J. Lopez (Eds.). Handbook of positive psychology (pp. 715 - 728). Oxford: Oxford University Press. 
Van Horn, J.E., Taris, T.W. Schaufeli, W.B. \& Schreurs, P.J.G. (in press). A multidimensional approach to measuring teacher wellbeing. Journal of Occupational and Organisational Psychology.

Wallace, J.R. \& Ipson, G.V. (1992). Workforce development: Business/university partnership. Economic Development Review, 10, 83-84.

Wheaton, B., Muthén, B., Alwin, D.F. \& Summers, G.F. (1977). Assessing reliability and stability in panel models. In D.R. Heise (Ed.), Sociological methodology (pp. 84-136). San Francisco: Jossey-Bass.

Wissing, M.P. \& Van Eeden, C. (2002). Empirical clarification of the nature of psychological well-being. South-African Journal of Psychology, 32, 32-44.
Zhao, J. \& Guo, J. (2002). The restructuring of China's higher education: An experience for market economy and knowledge economy. Educational Philosophy and Theory, 34, 207-215.

Zijlstra, F. \& De Vries, Y. (2001). Burnout en de bijdrage van socio-biografische en werkgebonden variabelen [Burnout and the contribution of socio-demographic and work-related variables]. In I.L.D. Houtman, W.B. Schaufeli \& T. Taris, (Eds.), Psychische vermoeidheid en werk: Cijfers, trends en analyses [Psychic fatigue and work: Number, trends and analyses] (pp. 83-106). Alphen a/d Rijn: Samsom. 